\title{
A ARTE DA CANTARIA AO LONGO DA ESTRADA REAL - AS PRODUÇÕES DO SÉCULO XVIII NO CAMINHO DO OURO EM ABORDAGENS MULTIDISCIPLINARES
}

Daniela Viana ${ }^{1}$

Prof. Dr. Carlos Alberto Pereira ${ }^{2}$

\section{Resumo}

A comunicação apresenta o projeto em andamento de preservação, ao longo da chamada Estrada Real, do patrimônio material e dos conhecimentos da arte da cantaria desenvolvido em parceria por pesquisadores de universidades de São Paulo e Minas Gerais. Essa experiência multidisciplinar envolve a abordagem de metodologias diversas e serve de base para "o debate e a reflexão crítica a respeito das metodologias utilizadas na produção historiográfica da arte", como propõe esse II EHA. A arte do trabalho da pedra conhecida como cantaria (abrangendo seus saberes internos, formas de trabalho e produções) é o alvo desse trabalho de levantamento, catalogação e disseminação de conhecimento através da conscientização patrimonial.

\begin{abstract}
The communication presents the project of preservation, in progress, around the colonial Real Road. It is focused on the material patrimony and the knowledge of the stone masonry art and developed by universities researcher of Minas Gerais and São Paulo, in partnership. This experience involves the boarding of diverse methodologies and helps to consolidate the debate and the critical reflection regarding the methods used in the history of art. The stone masonry art (including its forms of work and productions) is the target of this work of survey, cataloguing and dissemination of knowledge.
\end{abstract}

Palavras-chave: cantaria, patrimônio, ciclo do ouro

\section{As Estradas Reais}

A procura de metais e pedras preciosas nas colônias portuguesas foi muito incentivada pela Coroa. Com a descoberta dessas riquezas no sertão brasileiro em fins do século XVII, o movimento desenfreado de aventureiros na chamada corrida do ouro levou à necessidade de uma fiscalização mais rígida por parte da metrópole. O deslocamento antes estimulado, no século XVIII passou a ser regrado.

$\mathrm{Na}$ tentativa de controlá-los naquelas regiões remotas foram criadas as Estradas Reais como únicos caminhos oficialmente permitidos para acesso às ricas terras produtoras. A abertura ou mesmo uso de caminhos alternativos eram tidos como crimes de lesamajestade, como forma de garantir o interesse fiscal da Coroa Portuguesa.

È importante frisar que não se trata de uma única estrada real e sim de uma junção de pelo menos três caminhos principais conhecidos como: Caminho Velho, Caminho Novo e Caminho da Bahia ou Rota dos Diamantes.

O Caminho Velho, como o próprio nome indica, foi o constituído anteriormente, por volta de 1674 a $1681^{3}$, durante a bandeira de Fernão Dias. A pedido do próprio rei de

\footnotetext{
${ }^{1}$ Instituição: Instituto de Filosofia e Ciências Humanas - Unicamp. E-mail: danivian@,unicamp.br

2 Instituição: Depto. Engenharia de Minas - UFOP. E-mail: pereira@demin.ufop.br Endereço para contato: Logradouro / $\mathrm{n}^{\mathrm{o}}$ Avenida Leopoldino de Oliveira / 2925, Complemento apt 1100, Cidade / UF Uberaba / MG, País / CEP Brasil / 38015-000
} 
Portugal, o bandeirante teria saído de São Paulo a busca de pedras preciosas. Ao longo do trajeto, para garantir a sobrevivência em longo prazo, plantaram roças e desenvolveram criações de pequenos animais como porcos e aves em áreas de parada e descanso. Essas áreas deram origem às primeiras vilas com a descoberta do ouro de aluvião nos rios Doce, das Velhas e das Mortes.

Após 1698, o filho de Fernão Dias, Garcia Rodrigues Pais, contratado pela Coroa, abriu o caminho que ligava o Rio de Janeiro a Minas Gerais. Esse ficou conhecido como Caminho Novo, o mais importante dos três no período colonial.

Já o Caminho da Bahia ou Rota dos Bandeirantes, que liga a região das minas ao Distrito Diamantino, teve função primordial no abastecimento da região com o acesso às fazendas de gado junto aos rios São Francisco e das Velhas.

Dessa maneira, esses caminhos oficiais se tornaram eixos importantes na demarcação do território e na formação de povoados e vilas ao longo do trajeto. Uma parte considerável do patrimônio artístico e histórico nacional do século XVIII se encontra depositada nesses antigos lugarejos.

Para garantir o bom uso dos caminhos oficiais, foram feitas obras em pedra como calçamentos, murros de arrimo, pontes, chafarizes, que em meio a um espaço natural exuberante conformam paisagens encantadoras. As Estradas Reais, elas próprias, configuram monumentos de valor ímpar e muito pouco conhecido.

Segundo a FAPEMIG, a

Estrada Real abrange 162 municípios de Minas, oito do Rio de Janeiro e sete de São Paulo, em um total de 1.400 quilômetros. A região se destaca por seu grande potencial turístico e por sua riqueza histórico-cultural. Apesar da importância da rota no povoamento e colonização dessa parte do território brasileiro, há pouco material registrado sobre o assunto ${ }^{4}$.

O potencial turístico desse trajeto, hoje em dia, já começa a ser aproveitado e valorizado por diferentes instituições. Recursos públicos e privados de órgãos governamentais e empresas como Ministério do Turismo, Secretaria de Turismo do Estado de Minas Gerais, Senac-MG e a Embratur são destinados a proteger, recuperar o seu patrimônio cultural e viabilizar o desenvolvimento econômico, além de reafirmar a sua importância histórica. ${ }^{5}$

A proposta do projeto aqui apresentado vai além de um incentivo turístico. $O$ principal objetivo é despertar, desenvolver e fomentar nas comunidades locais, dos municípios ao longo do trajeto, atitudes de respeito, valorização e preservação do Patrimônio Cultural da Estrada Real.

A Universidade Federal de Ouro Preto tem vários projetos que se integram dentro das ações de valorização das comunidades incluídas nos caminhos reais, como Ouro Preto e Mariana. Alguns desses trabalhos são voltados para o resgate de tradições locais, como o trabalho de resgate do saber-fazer dos oficiais de cantaria em Minas Gerais. Também são

\footnotetext{
${ }^{3}$ Fernão Dias teria morrido de malária, em 1681.

${ }^{4}$ www.fapemig.br

${ }^{5}$ A Secretaria de Turismo de Minas Gerais criou diversos circuitos turísticos, entre eles o Circuito da Estrada Real. A lei estadual 13.173/99 cria o Programa de Incentivo ao Desenvolvimento do Potencial Turístico da Estrada Real.
} 
desenvolvidas atividades voltadas para a preservação patrimonial com programas de extensão nas escolas do Ensino Fundamental de Ouro Preto. ${ }^{6}$ Neste projeto, a atenção e os esforços estão atentos à presença de uma antiga técnica de entalhar e aparelhar as rochas, chamada de cantaria, ao longo do trajeto dos caminhos reais. ${ }^{7}$

Nesse sentido, propõe-se um projeto que realizará um inventário fotográfico e histórico de um conjunto significativo de monumentos feitos com a técnica da cantaria na Estrada Real, além de um encontro entre os artífices da pedra para discutir e registrar as suas técnicas de trabalho. A partir das informações levantadas e das imagens produzidas pretende-se realizar um livro que apresentará a arte da cantaria e servirá como um guia/roteiro para os monumentos e/ou artesãos que se encontram ao longo da Estrada Real, desde Diamantina até Parati. Também com as imagens produzidas, serão realizadas exposições itinerantes acompanhando oficinas com palestras, nas principais cidades do eixo (Serro/Diamantina, Ouro Preto/Mariana e Tiradentes/São João Del Rei) e em Belo Horizonte.

O levantamento e a divulgação dessas informações abrangem atividades interdisciplinares e o envolvimento dos diversos saberes para a divulgação ao público em geral. Fazem parte da equipe professores e alunos das Universidades Estadual de Campinas (Unicamp), da Federal de Ouro Preto (UFOP) e da Federal de Minas Gerais (UFMG). O projeto multidisciplinar envolve arquitetos, historiadores, engenheiros, fotógrafos e técnicos.

\section{A Arte da Cantaria}

A cantaria está presente em pontes, chafarizes, cruzeiros, moradias, calçamentos, demarcando visualmente o espaço colonial. Ela nos revela um rico universo de informações sobre história, arte, materiais e técnicas construtivas existentes nas cidades surgidas no Brasil, especialmente aquelas erguidas em decorrência das descobertas do ouro no interior da colônia no século XVIII.

O conhecimento relativo a essa arte era passado durante muito tempo de forma oral, como segredos profissionais. A fábrica ou oficina de cantaria era o espaço onde se dava a aprendizagem de maneira tradicional. Com a crise do ouro e a diminuição quase total da produção das obras arquitetônicas de pedra da região, esse conhecimento foi se perdendo.

Em muitos casos, ao longo do século XX, as obras originais de pedra de cantaria, quando danificadas, foram substituídas por peças de concreto. Um dos motivos era a falta de mão de obra especializada para produzir a peça de substituição e a grande falta de conhecimento a respeito da importância da técnica na definição da obra e do patrimônio.

\footnotetext{
${ }^{6}$ Cf. SILVA, Fabiano Gomes da et al. OFICINA DE CANTARIA DE OURO PRETO: resgate de ofício, formação de mão-de-obra e preservação Patrimonial. In: VII CONGRESSO IBERO-AMERICANO DE EXTENS ÁO UNIVERSITÁRIA, 8: 2005 nov: Rio de Janeiro (RJ). Rio de Janeiro, 2006. (no prelo); SILVA, Fabiano Gomes da et al. EDUCAÇÃO PATRIMONIAL: revisitando Ouro Preto através da cantaria. In. CORRÊA, Edison José et al. (Re)conbecer diferenças, construir resultado. Brasília: UNESCO, 2004. pp.121-128.

7 SILVA, Fabiano Gomes da. CONSTRUTORES MINEIROS: os canteiros de Vila Rica no século XVIII. In: ENCONTRO REGIONAL DE HISTÓRIA, 14: 2004, jul: Juiz de Fora(MG). [Eletrônicos] Juiz de Fora: ANPUH(MG), 2004. CD-ROM
} 
Um bom exemplo disso é a comparação entre as pontes antigas e as recém construídas ao longo da Estrada Real. A imagem 1a apresenta a antiga ponte feita de pedra seguindo a arte da cantaria na junção das partes e cortes precisos. Repare a força da estrutura que resistiu a mais de 200 anos de intempéries e desgastes mantendo a beleza da pedra natural e a harmonia com a paisagem. A imagem 2 mostra o mestre canteiro Seu Juca sentado sobre um modelo de ponte de cantaria explicando a forma com a correta união das pedras, mesmo sem um material aglutinante mantém a firmeza da estrutura que se move dentro de um limite seguro para garantir a resistência e durabilidade.

Já a Imagem 1 b apresenta uma ponte recentemente construída com cimento e usando a pedra apenas com o sistema de gabião, muro de sustentação feito de pedras arrumadas dentro duma tela. Seu tempo de vida é muito menor que a construídas com a técnica de cantaria.
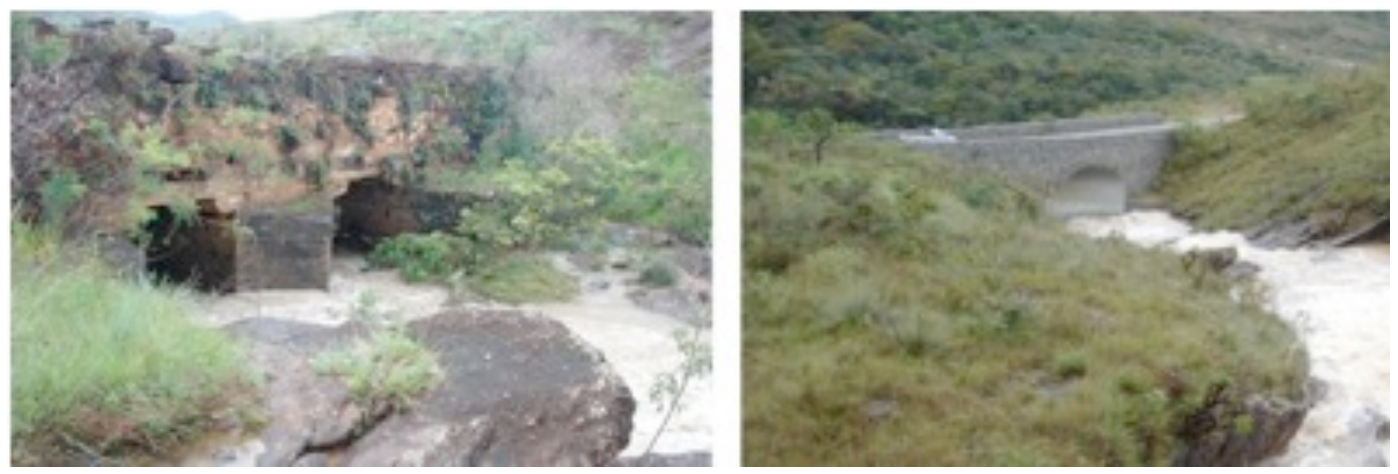

Imagem 1

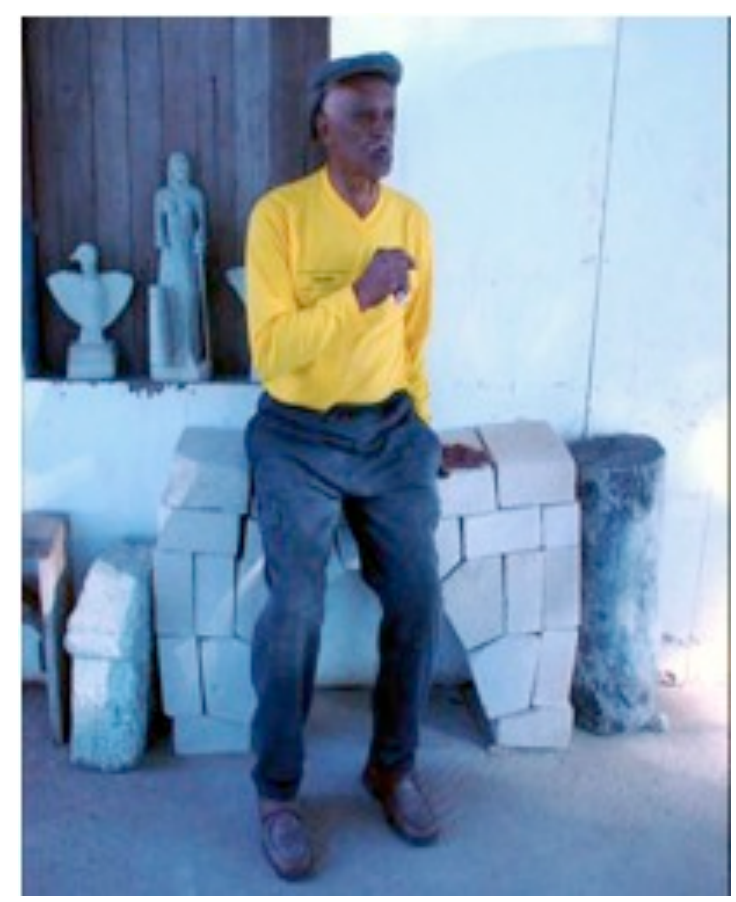

Imagem 2 


\section{Mestres Canteiros}

O projeto que aqui apresentamos prevê encontros entre profissionais que atuam na região para discutir as técnicas usadas por cada grupo, trocar experiências, documentar seus conhecimentos e garantir a preservação da arte da cantaria com oficinas voltadas para o público jovem. O trabalho de alguns mestres canteiros remanescentes e seus conhecimentos fazem parte do patrimônio imaterial da região. O grande exemplo disso é sem dúvida o saudoso Mestre Juca, falecido poucos dias depois dessa comunicação ter sido apresentada ${ }^{8}$.

Mestre Juca começou sua relação com a pedra trabalhada ainda jovem, em 1939, como servente na implementação do Museu da Inconfidência em Ouro Preto. O trabalho foi comandado por estrangeiros especializados que não gostavam de ter curiosos, como ele, espreitando seus segredos de ofício. Assim, muito do que Seu Juca aprendeu se deveu mesmo à sua capacidade autodidata.

O tempo passou, ele se aposentou como mestre de obras da antiga Alcan e, na década de 1980, por acaso, Seu Juca se voltou definitivamente à arte da cantaria.

Quando derrubaram uma das pinhas da Ponte do Pilar como de costume, infelizmente, a primeira iniciativa era refazê-la em concreto. Seu Juca, entretanto, a refez em quartizito original e deste então, participou de várias outras restaurações preciosas.

Seu trabalho recebeu várias homenagens, honrarias e condecorações como a Ordem do Mérito Cultural em 2002 e aos 78 anos ele participou do curso de especialização em Restauração de Cantaria no Centro Europeu de Veneza, Itália, a convite do projeto Monumenta/BID.

Desde 2004, Mestre Juca recebia os alunos do curso de Arquitetura e Urbanismo da Unicamp em sua Oficina de Cantaria na UFOP. Aproveitando um espaço que servia como garagem de Ônibus, o Prof. Dr. Carlos Alberto Pereira coordena essa iniciativa exemplar. Lá, o simpático senhor com seus mais de 80 anos, não só trabalhava a pedra para restauro de monumentos ameaçados como ensinava o ofício, em risco de extinção, a crianças e adultos.

Sem dúvida fará muita falta. O consolo é saber que sua passagem nesse mundo não foi vã. Suas iniciativas, seus trabalhos e ensinamentos são um estimulo e incentivo para a continuidade e faz parte da gênese desse projeto de valorização da cantaria ao longo da Estrada Real.

\section{Exposição fotográfica paralela}

Durante o II Encontro de História da Arte, foi realizada uma exposição fotográfica na Casa Cultural do Lago, no campus da Unicamp. Os fotógrafos amadores Rogério Ribeiro e Edson Françozo apresentaram suas visões de Ouro Preto ao lado dos desenhos do aluno Francisco Andrade em uma pequena mostra organizada pelo Prof. Dr. Marcos Tognon e Prof. Ms. Daniela Viana Leal.

\footnotetext{
8 Mestre Juca finalizou seus dias em casa, em Ouro Preto, cercado pela família, na quarta feira, dia 29/03/2006. Ele foi o grande incentivador desse projeto e por isso aproveito para fazer aqui uma pequena apresentação de sua trajetória profissional como forma de homenagem póstuma.
} 